\title{
Closure of residual palatal fistulae and oronasal communications from various etiologies, using the resilient and versatile dorsal pedicled tongue flap
}

\author{
Colonel (Dr) Priya Jeyaraj* \\ Classified Specialist (Oral \& Maxillofacial Surgery), Deputy Commandant and Officer in Charge Trauma \& Rehabilitation, Command Military Dental Centre \\ (Northern Command), Jammu \& Kashmir, India
}

\begin{abstract}
Residual defects of the palatal region following ablative resection of tumors and Gunshot wounds (GSWs) of the maxillofacial region can be quite painstaking, daunting and challenging to reconstruct due to the extent and composite nature of the tissue loss. A shortage of available donor areas and local flap options in the intraoral region adds to the difficulty. The tongue flap is an extremely versatile, sturdy, efficient and reliable local flap useful for reconstruction of various intraoral composite tissue defects, owing much of its success to its highly vascular structure, good mobility, texture match, central location and low donor site morbidity. In this case series, its value in providing a gratifying solution by permanently eliminating persistent residual oronasal fistulas, post ablative tumor resection and GSWs has been discussed. This article also describes some of the techniques which can be used to alleviate possible shortcomings of the tongue flap, such as, flap dehiscence and detachment during the early post operative period resulting from normal tongue movements.
\end{abstract}

\section{Introduction}

Oro nasal communications are often encountered following trauma, ablative resection for tumors, Gunshot injuries and most commonly, after previous attempts at closure of palatal and /or alveolar clefts.

Reconstruction of intraoral defects is of great importance in order to preserve the unique anatomy and functions of the oral cavity like mastication, taste, swallowing, control and disposal of saliva, and phonation [1]. Tissue defects in the oral region should be replaced with tissues, which have the best anatomical, histological, and functional similarity. Therefore, neighboring tissues seem to be the best donor site alternative [2]. Intraoral local flaps including palatal island flap, buccinator myomucosal flap, facial artery musculomucosal flap, buccal fat pad flap, have been used in the past to reconstruct intraoral defects [3]. The location and size of the intraoral defect would determine the reconstruction method of choice, such as primary closure, mucosal or skin grafts, local and regional flaps, and free tissue transfers [4].

Because of the inadequacy of tissue around anterior palatal fistulas, local mucoperiosteal flaps are of limited value in their closure. In such cases, tongue flaps have been found extremely useful in intraoral defect reconstruction [5].

In this Case Series, the value of the dorsal pedicled tongue flap in the successful closure of residual Oronasal fistulas following GSWs and tumor ablation, have been presented.

\section{Case series}

Two adult male patients, of ages 25 and 27 respectively reported with complaints of escape of air into the mouth while breathing, nasal regurgitation of food and fluids, halitosis and a nasal twang and intonation in their voices. History revealed that they had sustained Gunshot injuries to the face in separate incidents, 18 and 20 months ago, for which they had been operated (Figures 1,5). Healing of the wounds had been satisfactory following surgery, except for the persisting Oronasal communications (Figures 2,6), which was the cause for their presenting complaints. On examination, each of the patients had a through and through palatal defect of 1.5 and $2 \mathrm{~cm}$ respectively. The surrounding palatal tissues appeared scarred and fibrosed (Figures 2C,D,6A).

The third patient, aged 24 years, had been operated for pleomorphic adenoma of the minor salivary glands in the anterior palate region (Figures 8A-E). Following the wide local excision that was carried out, he developed a persistent oronasal communication (Figures $8 \mathrm{~F}-\mathrm{H}$ ).

In all these three patients, feasibility of local palatal mucoperiosteal flaps for reconstruction of the defect was ruled out owing to the traumatized, scarred, fibrosed and inadequate quality of the palatal tissues. An anteriorly based dorsal pedicled tongue flap seemed to be the most viable option, and the patients were explained as to the procedure and the post operative limitations in speech and eating unit that they would experience, until surgical detachment of the pedicle.

In all patients, the first surgical session was carried out under general anesthesia. The palatal defect was closed with the tongue flap after freshening the margins of the recipient site (Figures 3,6,9).

Correspondence to: Colonel (Dr) Priya Jeyaraj, Classified Specialist (Oral \& Maxillofacial Surgery), Deputy Commandant and Officer in Charge Trauma \& Rehabilitation, Command Military Dental Centre (Northern Command), Jammu \& Kashmir, India, Tel: (91)9596840303; E-mail: jeyarajpriya@yahoo.com

Key words: tongue flap, intraoral reconstruction, gsw (gunshot wounds), palatal fistula

Received: June 12, 2017; Accepted: July 04, 2017; Published: July 06, 2017 


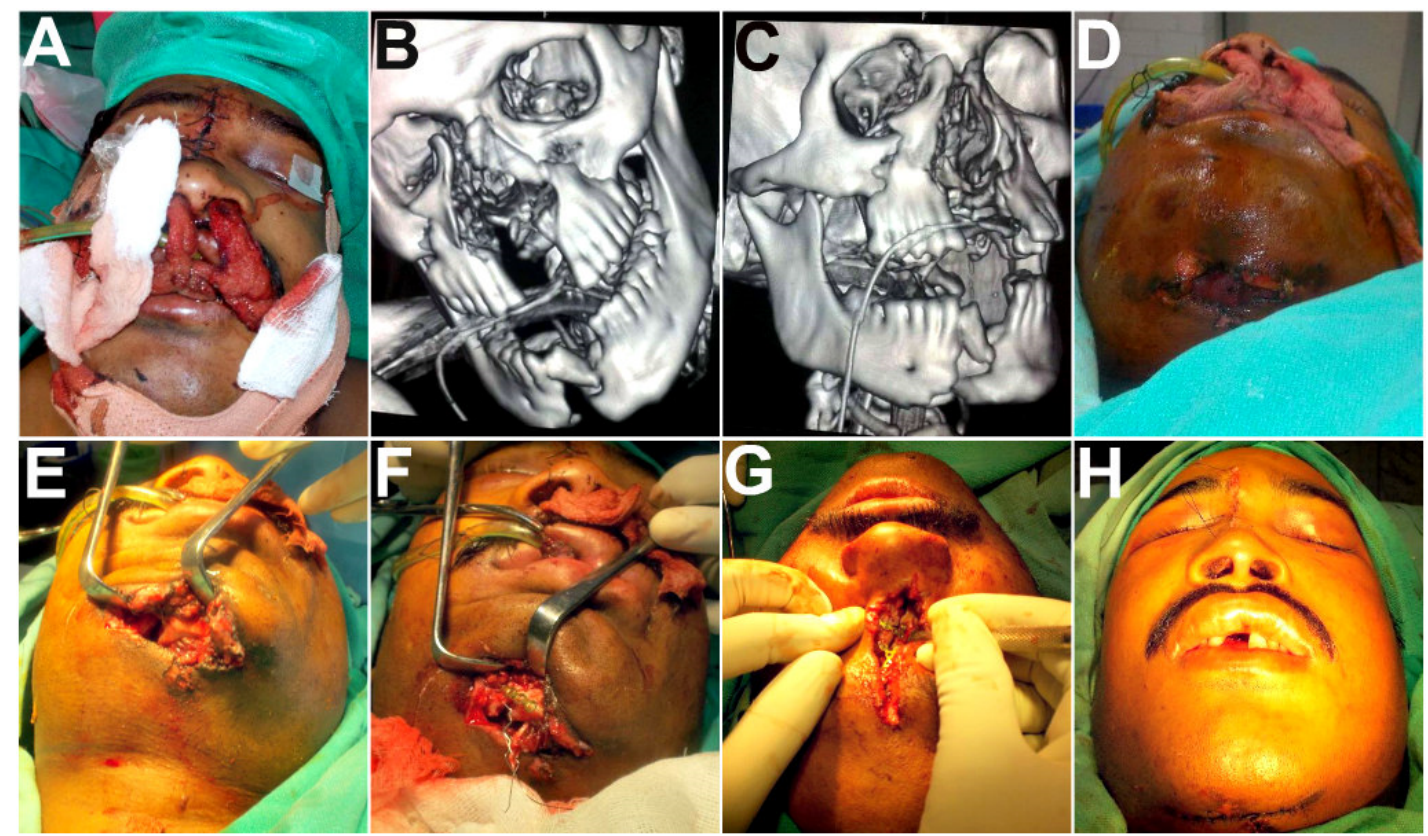

Figure 1A-D. A case of Gunshot injury of the maxillofacial region. Fractured maxillae widely splayed apart with tearing and destruction of the palatal tissues. E-H: Open reduction and internal fixation of fractured maxilla, mandible, nasoethmoid complex carried out together with soft tissue closure.

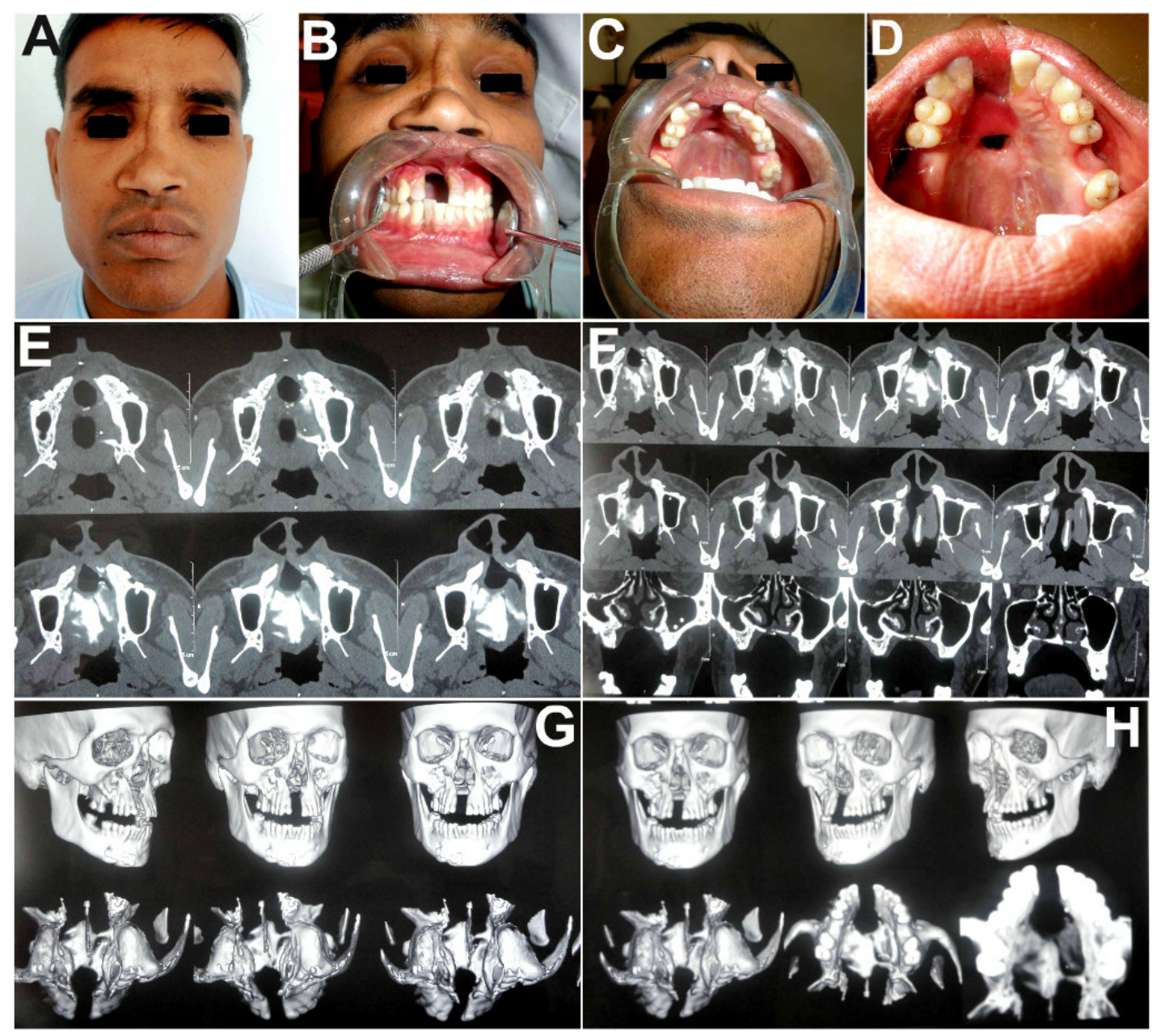

Figure 2A-D. Patient presented 18 months later with a persisting residual palatal fistula. E-H: CT scans revealing the composite anterior palatal defect with the resultant wide oronasal communication. 


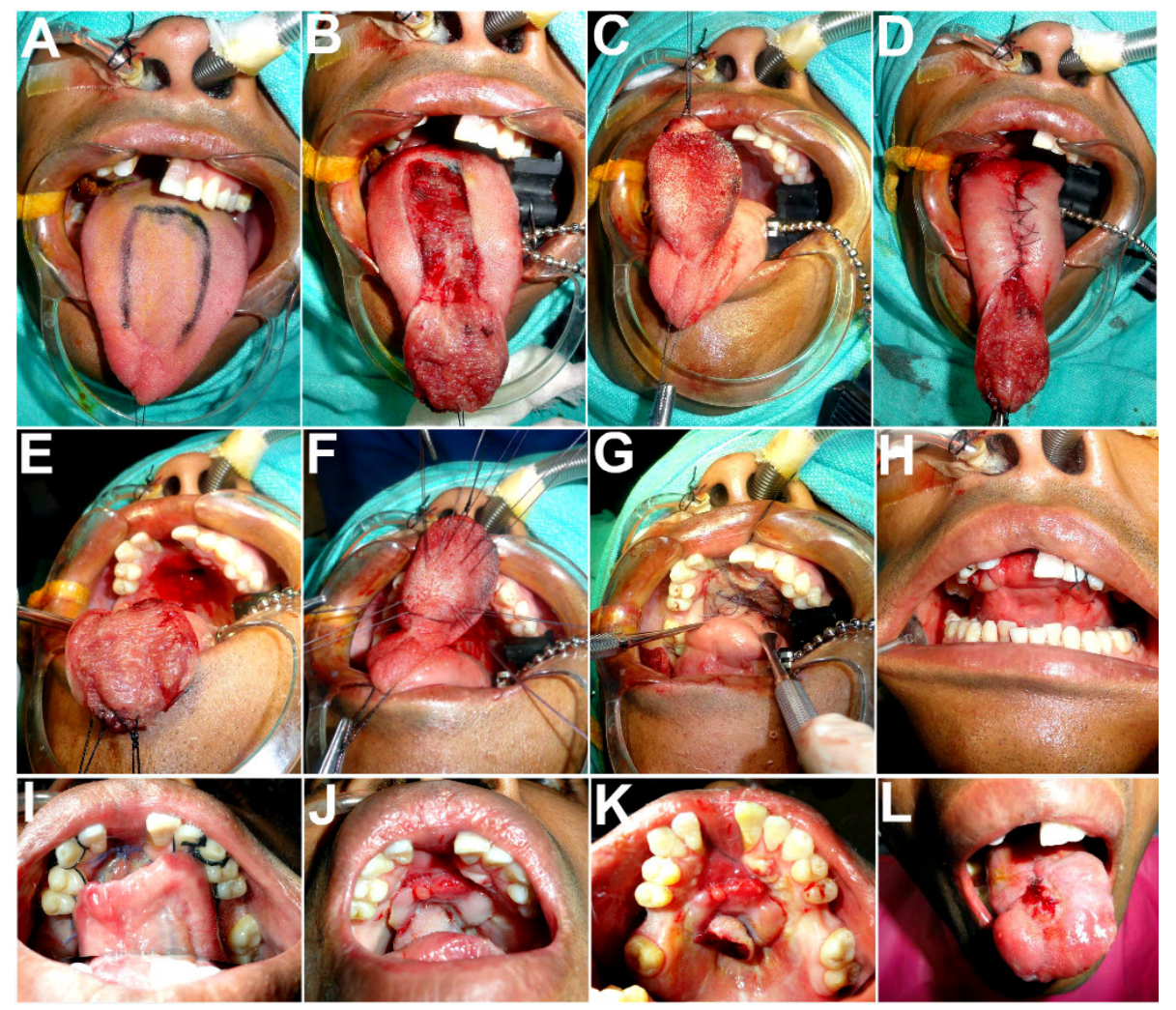

Figure 3A-D. An anteriorly based dorsal pedicled tongue flap outlined and raised, with simultaneous primary closure of the donor site defect. E-G: Flap upturned and sutured at the palatal defect after adequate freshening of the margins of the recipient site. H: The tongue was then tethered to the maxillary teeth. I-L: Cutting of the flap pedicle carried out under local anesthesia, on the $22^{\text {nd }}$ postoperative day.

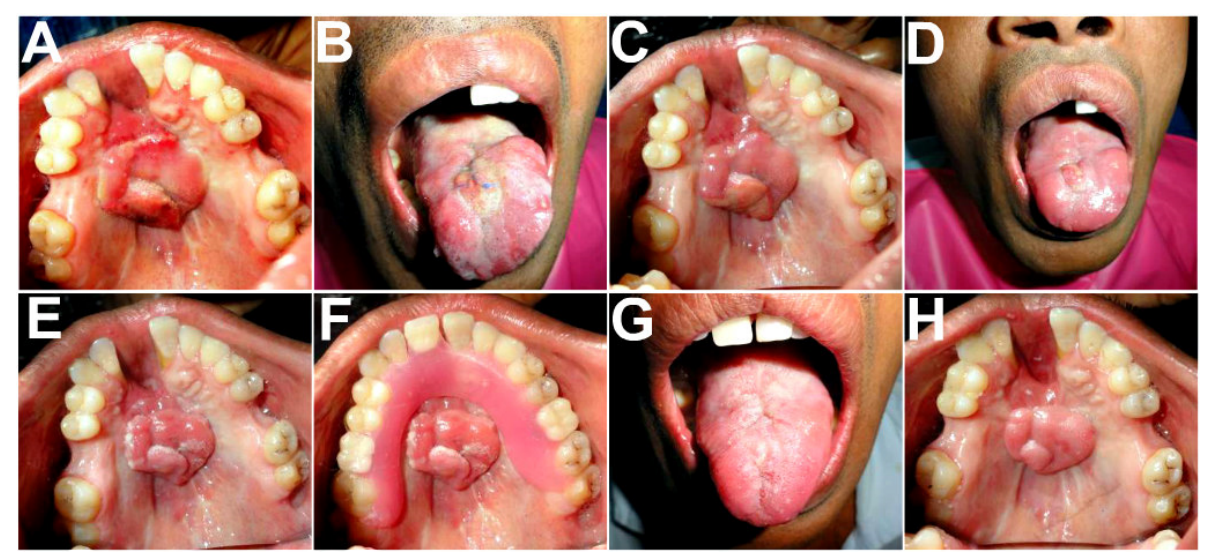

Figure 4A-F. Appearance on the $3^{\text {rd }}, 7^{\text {th }}$ and $15^{\text {th }}$ days following cutting of the pedicle, showing a sturdy and healthy tongue flap successfully obliterating the palatal defect. Minimal scarring of the donor site, with the tongue retaining its full movements and functions. G,H: Appearance after 2 months, showing the fully recovered donor site and an excellent colour and texture match of the tongue flap at the recipient site, with the adjacent palatal mucosa.

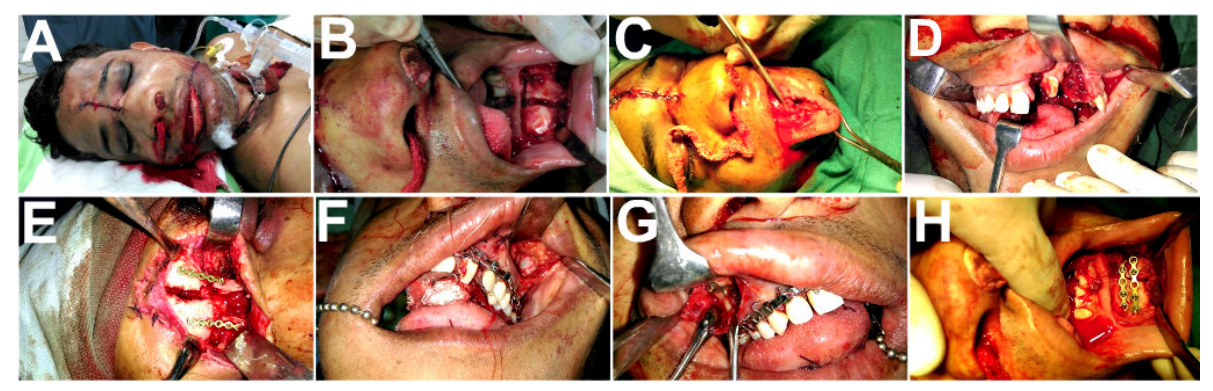

Figure 5. Panfacial fractures sustained in a Gunshot injury, managed by open reduction and semirigid internal fixation, with primary closure of the soft tissue injuries. 


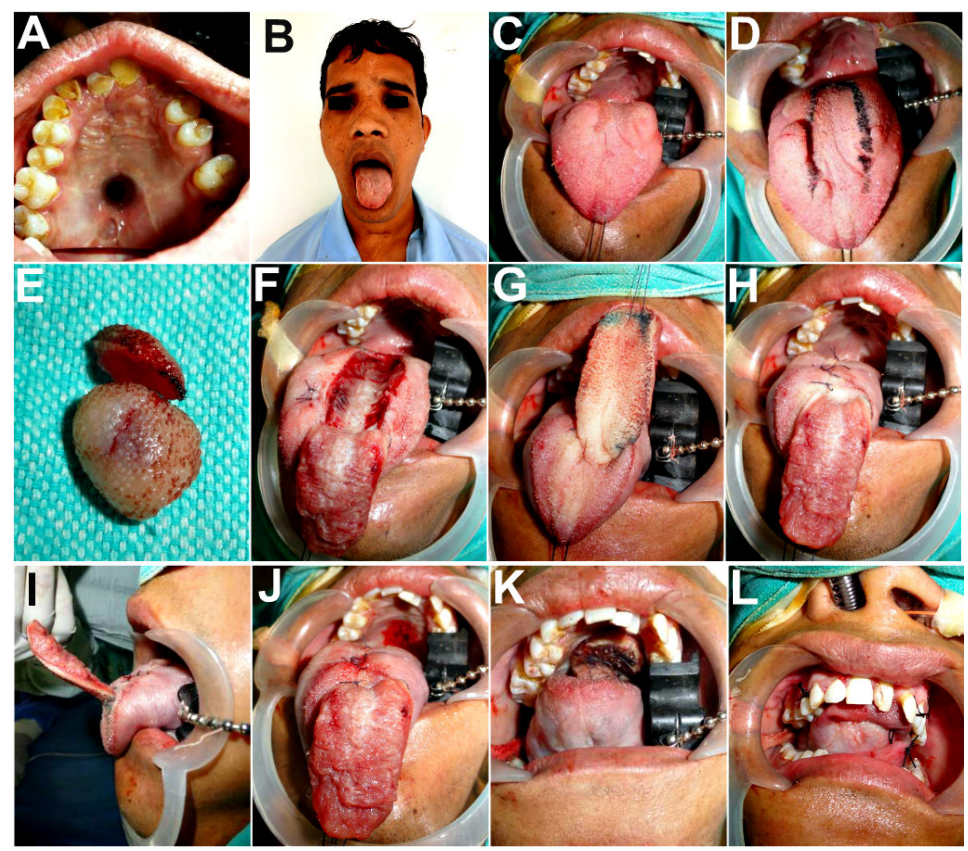

Figure 6A-C. 20 months following surgery, patient presented with a large residual oronasal fistula. The palate appeared pale, scarred and fibrosed, and the tongue had multiple scared areas owing to the old bullet injury through these tissues. D,E: Tongue flap outlined, fibrotic mass excised from the tongue dorsum. F-J: Anteriorly based flap raised and the donor site closed with resorbable sutures. K,L: Flap flipped upward and sutured to the freshened margins of the palatal defect. The tongue was then tethered to the upper teeth to restrain its movements in the postoperative period.

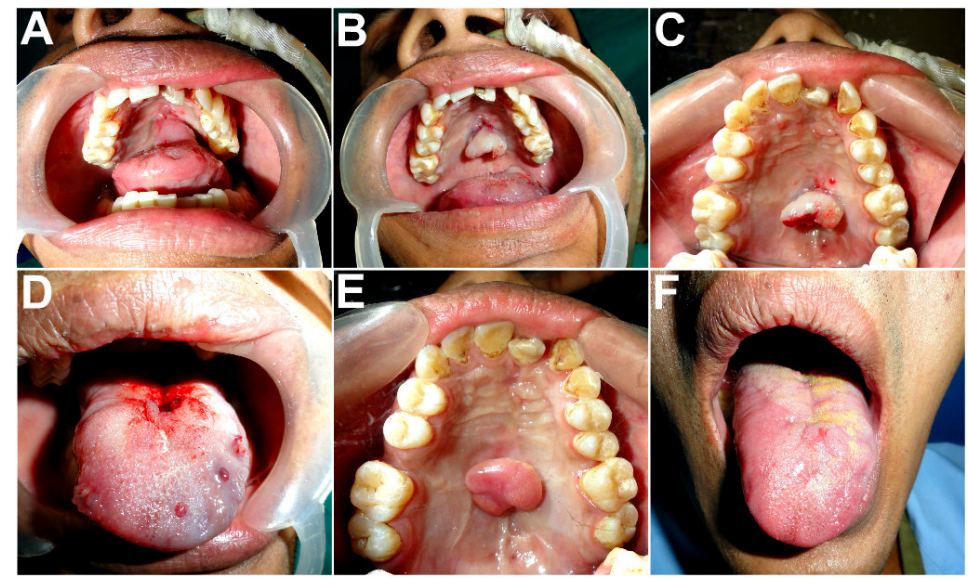

Figure 7A-D. Depedicling of the tongue flap carried out under local anesthesia on the $22^{\text {nd }}$ postoperative day. E,F: Appearance after 2 months, showing a sturdy flap effectively sealing off the oronasal communication and filling the palatal defect. Good mucosal texture match with the adjacent tissues. Barely perceptible donor site on the tongue.

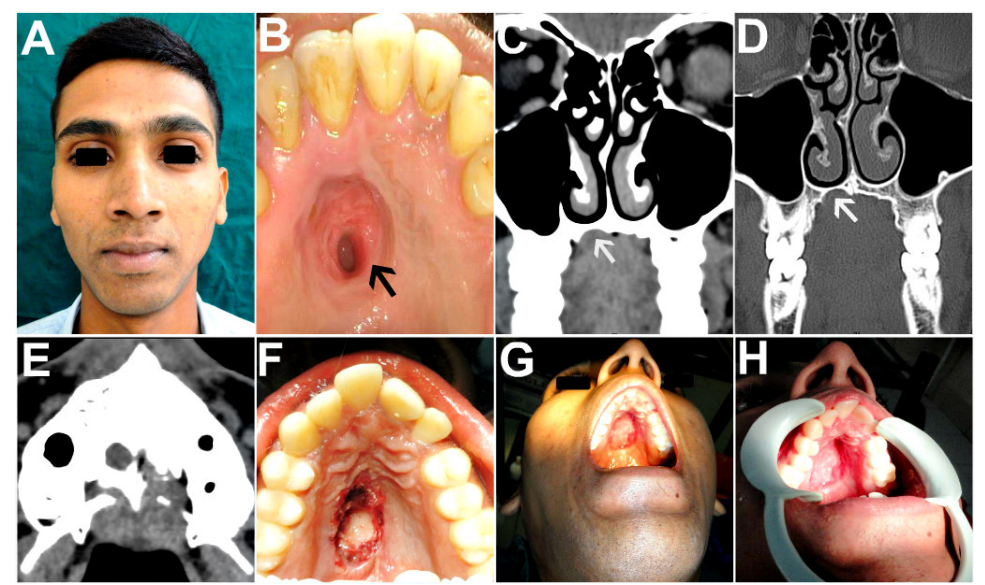

Figure 8A,B. A 24 year old patient with a non healing ulcer of insidious onset in the hard palate region, diagnosed as pleomorphic adenoma of minor salivary gland. C-E: CT scan revealed bony erosion of the anterior hard palate, as indicated by the white arrows. F-H: Wide local excision carried out which included both surrounding safe margins of palatal mucosa as well as palatal bone, thus creating a oronasal communication. Histopathological examination of excised tissue confirmed the diagnosis and ruled out any evidence of malignancy. 
Following suturing of the dorsal tongue flap in place, three silk sutures were drawn through the tongue, one at its tip and one through each of its lateral borders and each suture was slung around the nearest upper tooth and tied, thus adapting the tongue to the palate and reducing the traction on the attachment of the dorsal tongue flap, thereby preventing its detachment and further stabilizing the flap in place (Figures 3H,6L,9J). All three patients were maintained on Ryle's tube Nasogastric feeding for 21 days postoperatively. This was done in order to minimize movements of the tongue that would otherwise be unavoidable while eating/drinking and swallowing. Oral hygiene measures were undertaken using saline mouth rinses as well as gentle teeth cleaning using a finger with some toothpaste.

The patients were taken up under local anesthesia on the 22st postoperative day for the second surgical session, namely, transsection of the pedicle (Figures 3I-L,7A-D,10A-D). The palatal fistulas in all the patients healed successfully (Figures 4E-H,7E,F,10E-H), with no post operative complications such as bleeding, hematoma formation, congestion, infection, partial or total flap necrosis or flap detachment. The tongue flap at the recipient site remained healthy with no recurrence of the fistula in any of the patients in the two years follow up period. Their phonation improved dramatically and there was a complete resolution of the problem of nasal regurgitation of orally ingested fluids and food particles. There was observed no deformity or articulation defect resulting from the flap harvested from the tongue dorsum, in any of the patients (Figures 4G,7F,10H).

\section{Discussion}

The anteriorly based dorsal tongue flap was introduced by GuerreroSantos and Altamirano in 1966 for the surgical closure of a large palatal fistula [6]. In 1972 Cadenat et al described the rich submucous vascular plexus in the tongue and demonstrated that tongue flaps could be raised safely in any direction, even when only $3 \mathrm{~mm}$ thick [7]. Eiselsberg was the first to use the tongue in reconstruction of oral cavity [8]. Lexer reported the first posteriorly based pedicled tongue flap for coverage of a retromolar trigon defect occurring after oncological surgery [9]. The tongue flap when compared to other reconstructive options, such as palatal and buccal flaps, mucoperiosteal island flaps, tubed pedicled flaps, nasolabial flaps, temporalis muscle flaps, and radial forearm free flaps has the advantage of an abundant vascular structure with significantly decreased rates of fistula recurrence after surgery. The second advantage of dorsal tongue flaps is the ease of planning the flap in sufficient length, width, and depth needed for the location and dimension of the fistula [10]. The tongue flap has the advantage of giving a good volume by adding muscular tissue [11].

Though the tongue flap is an extremely versatile and efficient means of closure of anterior as well as posterior, unilateral and bilateral palatal defects and effectively functionally obliterates the oronasal communication, it has a few drawbacks. The main disadvantages of the tongue flap is the need for a second surgical procedure to detach the pedicle and the need for patient's compatibility with the procedure owing to functional loss like difficulty in swallowing and speech due to the immobile tongue till depedicling. Flap dehiscence and detachment during the early post operative period is a troublesome complication owing to tongue movements during normal activities such as speaking, swallowing, yawning, coughing etc. The unbridled tongue exhibits vigorous and continuous movements that often tug at the pedicle and result in flap detachment. Another disadvantage is the peroral appearance of the repaired area, the tongue tissue appearing

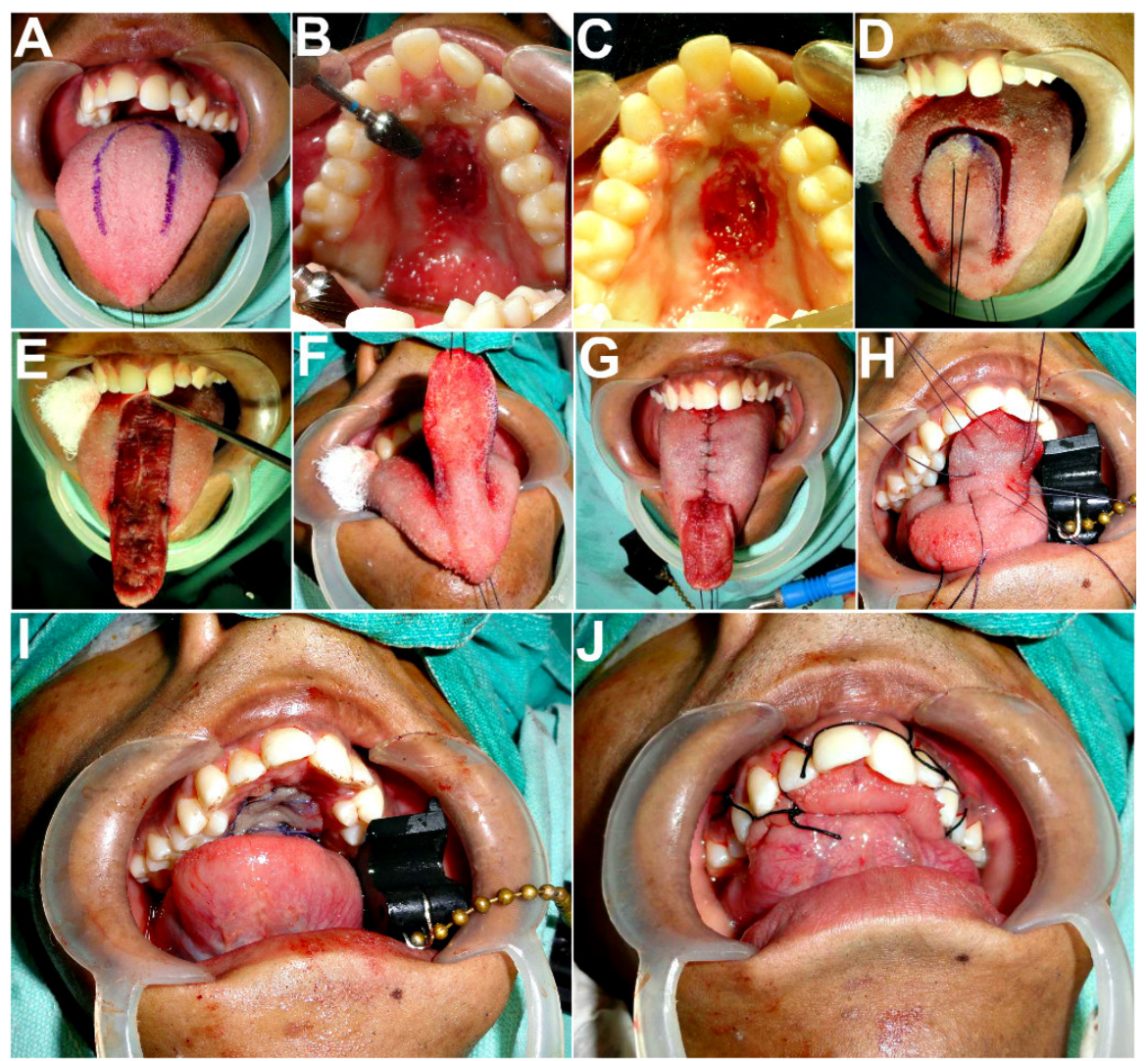

Figure 9. Residual palatal fistula resulted in a troublesome and persistent oronasal communication. Closure of the palatal defect carried out after freshening its margins, using the anteriorly based dorsal pedicled tongue flap. 

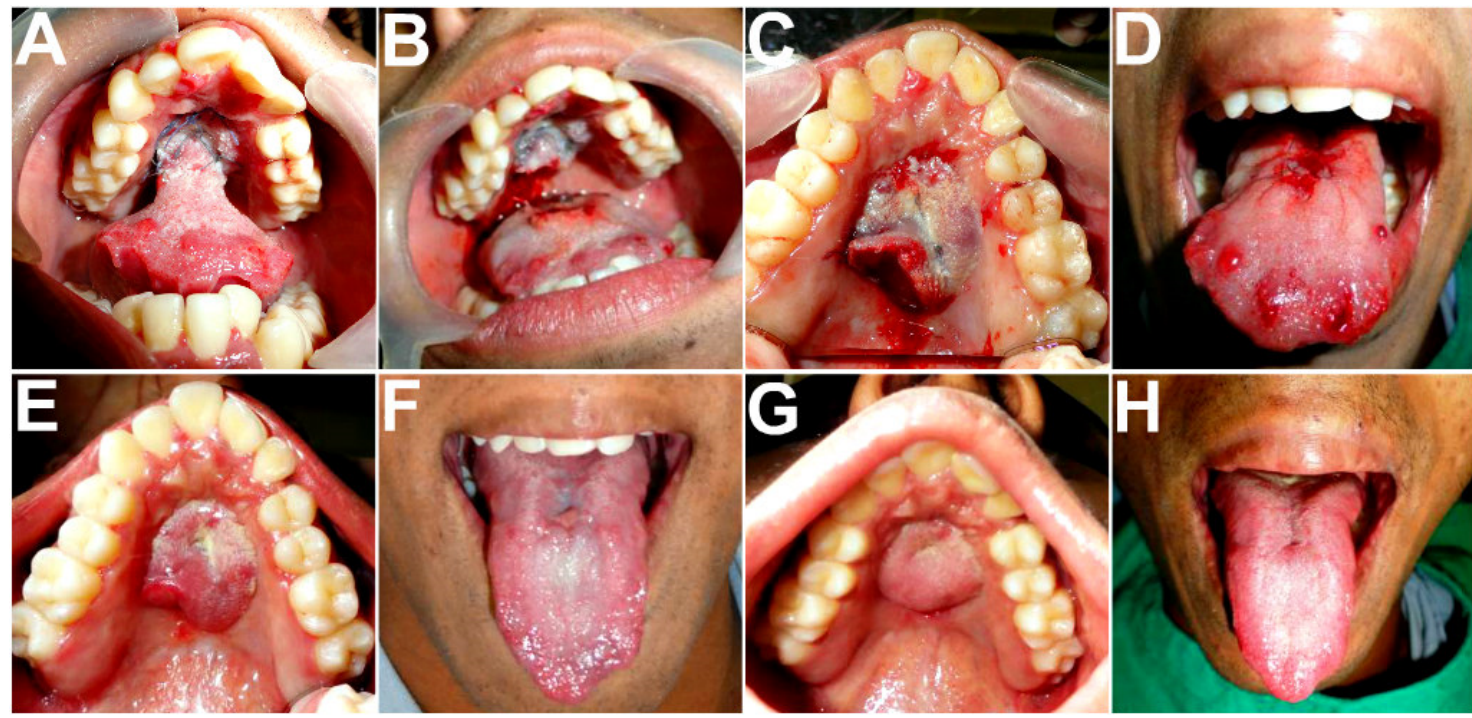

Figure 10A-D. Separation of the pedicle carried out on the $22^{\text {nd }}$ postoperative day. E-H: Two weeks and two months postoperative appearance showing an excellent take of the flap and no residual deformity of the tongue.

bulky, rough and rather unnatural in the roof of the mouth. This article describes some of the methods which can be used to alleviate these problems. In this study, all the patients were kept on Ryles Nasogastric tube feeding for the period of 21 days till separation of the pedicle. This was done with the aim to help keep the tongue as immobile as possible, with the flap securely adapted at the defect site, to give it the best chance to take uninterrupted, and to reduce the chances of flap detachment in the post operative period. All the patients were able to accommodate well with the procedure and there was no issue at all with patient compliance.

\section{Conclusion}

The tongue is an excellent donor site for oral soft tissue reconstruction especially for closure of palatal fistulas because of its proximity to all intraoral structures and texture match, highly vascular and sturdy structure, bulkiness of the subjacent muscle and less donor site morbidity. The few drawbacks that are encountered occasionally, such as flap detachment and dehiscence, can be prevented by ensuring minimal mobility of the tongue in the early post operative period. In GSWs and tumor ablative surgery, where composite tissue defects are involved, the tongue provides a reliable and efficient means of restoring lost tissue bulk as well as ensuring a permanent closure and sealing off of the oronasal fistulas.

\section{Compliance with ethical standards}

\section{Disclosure of potential conflicts of interest}

The author of this article has not received any research grant, remuneration, or speaker honorarium from any company or committee whatsoever, and neither owns any stock in any company. The author declares that she does not have any conflict of interest.

\section{Research involving human participants and /or animals}

All procedures performed on the patients (human participants) involved were in accordance with the ethical standards of the institution and/or national research committee, as well as with the 1964 Helsinki declaration and its later amendments and comparable ethical standards.

\section{Ethical approval}

This article does not contain any new studies with human participants or animals performed by the author.

\section{Informed Consent}

Informed consent was obtained from all the individual participants in this study.

\section{Funding}

This study was not funded by any organization/society.

\section{References}

1. Ceran C, Demirseren ME, Sarici M, Durgun M, Tekin F (2013) Tongue flap as a reconstructive option in intraoral defects. J Craniofac Surg 24: 972-974. [Crossref]

2. Joshi A, Rajendraprasad JS, Shetty K (2005) Reconstruction of intraoral defects using facial artery musculomucosal flap. Br J Plast Surg 58: 1061-1066. [Crossref]

3. Buchbinder D, St-Hilaire H (2003) Tongue flaps in maxillofacial surgery. Oral Maxillofac Surg Clin North Am 15: 475-486. [Crossref]

4. de Bree R, Rinaldo A, Genden EM, Suárez C, Rodrigo JP, et al. (2008) Modern reconstruction techniques for oral and pharyngeal defects after tumor resection. Eur Arch Otorhinolaryngol 265: 1-9. [Crossref]

5. Pigott RW, Rieger FW, Moodie AF (1984) Tongue flap repair of cleft palate fistulae. $\mathrm{Br}$ J Plast Surg 37: 285-293. [Crossref]

6. Guerrero-Santos J, Altamirano JT (1966) The use of lingual flaps in repair of fistulas of the hard palate. Plast Reconstr Surg 38: 123-128. [Crossref]

7. Assunçao AG (1993) The design of tongue flaps for the closure of palatal fistulas. Plast Reconstr Surg 91: 806-810. [Crossref]

8. von Domarus H (1988) The double-door tongue flap for total cheek mucosa defects Plast Reconstr Surg 82: 351-356. [Crossref]

9. Chicarilli ZN (1987) Sliding posterior tongue flap. Plast Reconstr Surg 79: 697-700. [Crossref]

10. Assunçao AG (1993) The design of tongue flaps for the closure of palatal fistulas. Plas Reconstr Surg 91: 806-810. [Crossref]

11. Guerrerosantos J, Trabanino C (2002) Lower lip reconstruction with tongue flap in paramedian bilateral congenital sinuses. Plast Reconstr Surg 109: 236-239. [Crossref]

Copyright: C2017 Jeyaraj CP. This is an open-access article distributed under the terms of the Creative Commons Attribution License, which permits unrestricted use, distribution, and reproduction in any medium, provided the original author and source are credited. 